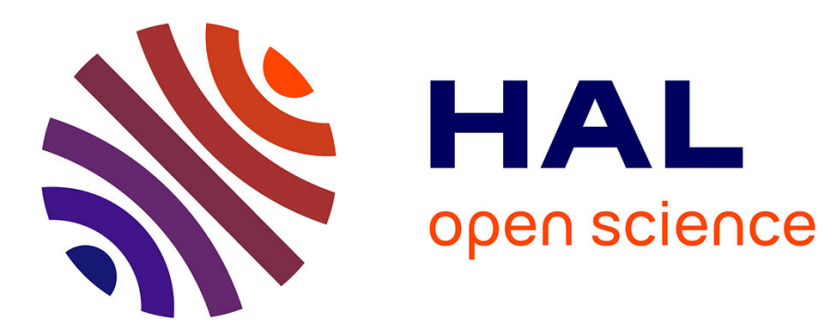

\title{
Capillary microplasmas for ozone generation
}

K. Hensel, Z. Machala, P. Tardiveau

\section{- To cite this version:}

K. Hensel, Z. Machala, P. Tardiveau. Capillary microplasmas for ozone generation. European Physical Journal: Applied Physics, 2009, 47 (2), pp.1-5. 10.1051/epjap/2009077 . hal-00480171

\section{HAL Id: hal-00480171 https://hal.science/hal-00480171}

Submitted on 3 May 2010

HAL is a multi-disciplinary open access archive for the deposit and dissemination of scientific research documents, whether they are published or not. The documents may come from teaching and research institutions in France or abroad, or from public or private research centers.
L'archive ouverte pluridisciplinaire HAL, est destinée au dépôt et à la diffusion de documents scientifiques de niveau recherche, publiés ou non, émanant des établissements d'enseignement et de recherche français ou étrangers, des laboratoires publics ou privés. 


\title{
Capillary microplasmas for ozone generation
}

\author{
K. Hensel ${ }^{1}$, Z. Machala ${ }^{1}$, P. Tardiveau ${ }^{2}$ \\ ${ }^{1}$ Division of Environmental Physics, Comenius University, Mlynska dolina F2, 84248 Bratislava, Slovakia \\ ${ }^{2}$ Laboratoire de Physique des Gaz et des Plasmas, Université Paris Sud, Bâtiment 210, 91400 Orsay, France
}

\begin{abstract}
Microplasmas inside confined cavities, pores and capillaries of dielectric materials present a great potential for various environmental applications. The paper briefly introduces the physical properties of the AC microplasmas generated by the discharges inside porous ceramics foams and focuses on their chemical effects in various mixtures of nitrogen and oxygen. Ozone formation as an example tool to evaluate the chemical potential of the microplasmas was investigated as a function of discharge power, gas mixture composition and total gas flow rate.
\end{abstract}

PACS. 52.80.-s Electric discharges, 52.75.-d Plasma devices

\section{Introduction}

Atmospheric pressure non-equilibrium microplasmas are very attractive for applications in areas such as surface modifications, environmental and biomedical processing. The advantage of the microplasmas is that they produce high densities of chemically active species at relatively low energy consumption without any vacuum equipment requirements. The atmospheric microplasmas can be generated by various types of electric discharges, including hollow cathode and capillary plasma electrode discharges [1-5], discharges in porous ceramics and capillary honeycombs [6-10] or dielectric barrier and coplanar discharges [11-13].

The capillary microplasmas (microdischarges) generated inside ceramic foams are short-living sparks. They originate from a surface barrier discharge, which develops on the ceramics at low amplitudes of the applied voltage. If the amplitude exceeds a certain value, the surface charges enter the micropores of the ceramics and capillary microdischarges form inside them. The transition of the 
microdischarge into an arc is suppressed by the small energy stored in the capacity of the electrodes and the connecting cables. The production of the charged particles in microplasmas is limited by the ambipolar diffusion toward the walls of the pores and volume recombination. The capillary microplasmas are relatively cold plasmas with high level of non-equilibrium. Their gas temperature was found close to room temperature, increasing with the oxygen contents in the gas mixture. Due to the high thermal shock resistance of the ceramic foams and effective heat dissipation, the overall temporal increase of the temperature is relatively small $[14,15]$.

The paper presents the generation of capillary microplasmas inside confined cavities of ceramic foams. It briefly describes the physical properties of the microplasmas and focuses on their chemical effects. The plasma chemical effects of the microplasmas were evaluated via the generation of ozone in various mixtures of nitrogen and oxygen. The dependence of ozone generation as a function of discharge power, gas mixture composition and total gas flow rate are presented.

\section{Experimental setup}

Figure 1 shows the experimental setup. The cylindrical discharge reactor consists of porous ceramic disk placed between two metal mesh electrodes. The disk is composed of mainly alumina and silica mixture and has diameter and thickness of 31 and $7 \mathrm{~mm}$, respectively. In the previous studies $[15,16]$ the optimal discharge spatial distribution was observed for the ceramics of $30 \sim 80 \mu \mathrm{m}$ pore size, therefore 50 and $80 \mu \mathrm{m}$ ceramics were selected for the presented tests. AC high voltage power supply was used for the generation of the discharge. The power was measured by digital multimeter Metex 3860M. The voltage at the reactor was measured by a high voltage probe LeCroy PPE20KV and the discharge current was measured using a current probe Pearson Electronics 2877 (1V/A) linked to the digitizing oscilloscope LeCroy LT374L (500 MHz, 4 GS/s). Ozone concentration measurement and gas mixtures analysis was performed by ozone analyzer BMT Messtechnik 964 and FTIR absorption spectrometer Perkin Elmer Spectrum BX II. Mixtures of nitrogen and oxygen (5, 10, 20, 50 and 100\%) with the total gas flow $0.4 \sim 2.0 \mathrm{~L} / \mathrm{min}$ were tested. The pressure drop across the discharge reactor measured by the digital manometer PCE P-30 was found negligible and ranged from 100 800 Pa for 
gas flow rates of 0.4 and $2.0 \mathrm{~L} / \mathrm{min}$, respectively.

\section{Experimental results and discussion}

\subsection{Discharge properties}

Our previous works [14-17] commented on the physical properties of microdischarges generated inside the ceramics foams by ac and dc driven discharges. The most detailed description of the discharge properties (based on the electrical measurements and visual observation) with respect to the effect of the pore size, discharge power, and gas mixture can be found in [15]. The results showed that the microplasmas inside the ceramic foam formed only for the specific discharge power and pore size of the ceramics. At small voltages, a surface barrier discharge on the surface of the ceramics may only be observed. With the increase of the applied voltage, however, the surface discharge transits into capillary microdischarges inside the ceramics, which onset voltage increases with the decreasing pore size. Upon the transition to microdischarges, the amplitude of the current pulses increases extremely, as well as the corresponding discharge current and power. The increase of the discharge current is larger for the bigger pore size, due to the increase of the radius of the discharge channel and volume of the generated microplasma. The optical observations by photography and emission spectroscopy showed the microdischarges were randomly distributed both in time and space and the consecutive microdischarges did not occur in the same point. Each microdischarge was accompanied by a light emission. In pure nitrogen, the light emission was homogenously distributed over the whole surface of the ceramics, but with the increase of oxygen and carbon dioxide in the mixture, the discharge homogeneity deteriorated. Optical emission spectroscopy also provides valuable information on active atomic or molecular species, and so gives insight in the plasma chemical processes in $\mathrm{N}_{2}$ and $\mathrm{O}_{2}$ mixtures. Figure 2 presents the emission spectra of microdischarges in the VIS-NIR region taken at constant voltage in the mixtures with various contents of oxygen. In nitrogen mixtures, the first and second positive systems of $\mathrm{N}_{2}$, and atomic lines of $\mathrm{N}$ and $\mathrm{O}$ were observed. The emission intensity of the spectral bands and lines increased with the applied voltage as a result of the increase of the number of discharge channels and the corresponding discharge current. The formation of the atomic oxygen 
and nitrogen is responsible for efficient generation of ozone molecules, but also other by-products generated by the microdischarges.

\subsection{Ozone Generation}

The plasma chemical effects of the microplasmas generated inside the ceramic foams were evaluated by tests of ozone generation in various mixtures of nitrogen and oxygen. The effect of the discharge power, the gas mixture composition and the gas flow rate are reported.

In pure oxygen, the concentration of generated ozone increased with the discharge power. For the given power, the concentration of ozone increased with decreasing gas flow rate (Fig.3). For example at the power of $2.5 \sim 3 \mathrm{~W}$, the ozone concentrations of 1034 and $293 \mathrm{ppm}$ were generated with gas flow rates of 0.4 and $2.0 \mathrm{~L} / \mathrm{min}$, respectively. However, considering the ozone concentration as a function of energy density $(\mathrm{J} / \mathrm{L})$ instead of discharge power, we found the concentration independent of the gas flow rate (Fig.4). The ozone yield ( $\mathrm{g} / \mathrm{kWh}$ ) decreased with both discharge power and energy density. The maximal yield of $45 \sim 55 \mathrm{~g} / \mathrm{kWh}$ was found for energy density of 20-30 J/L, while the minimal yield of $15 \sim 18 \mathrm{~g} / \mathrm{kWh}$ was found for $440 \sim 450 \mathrm{~J} / \mathrm{L}$, regardless of the gas flow rate.

In mixtures of nitrogen and oxygen, the concentration of generated ozone was generally found smaller than in pure oxygen. Considering the ozone production at the given discharge power, the highest concentration was observed in the mixture of $10 \%$ oxygen in nitrogen (Fig. 5). As the figure shows, the concentration of ozone reached 280 and $386 \mathrm{ppm}$ for gas flow rates 0.5 and $1.0 \mathrm{~L} / \mathrm{min}$, respectively. The corresponding ozone yield was 4.0 and $6.0 \mathrm{~g} / \mathrm{kWh}$, respectively. An unusual decrease of the ozone concentration with the increase of the oxygen contents in the initial mixture can be attributed to the homogeneity of the discharge distribution in the ceramics. As reported in [15], in the pure nitrogen the distribution of microdischarges inside the whole ceramics was relatively homogeneous. However, with the increase of the oxygen concentration the microdischarges concentrated particularly at the sharp edges of outer circumference of mesh electrodes. This nonhomogeneity of the microdischarge distribution, along with the increase of the discharge current and 
consequently the gas temperature caused that ozone concentration decreased with the increasing oxygen content. The increasing energy density and gas heating caused decomposition of the formed ozone molecules and supported formation of undesired by-products.

In the mixtures of nitrogen and oxygen, the effect of gas flow rate on the ozone generation was also found important. The gas flow rate determined the maximal concentration of ozone generated, which increased with the gas flow rate. Figure 6 shows the results for $20 \%$ of oxygen in the initial mixture. As the figure shows, for gas flow rate of $0.4 \mathrm{~L} / \mathrm{min}$ the maximal ozone concentration of $43 \mathrm{ppm}$ was found at $0.3 \mathrm{~W}$, while for $1.2 \mathrm{~L} / \mathrm{min}$ the maximum of $78 \mathrm{ppm}$ was found at $4.4 \mathrm{~W}$. The figure shows that the power corresponding to the maximum concentration increased with the gas flow rate. While the ozone concentration increased, reached maximum and subsequently decreased with increasing discharge power for all gas flow rates, the ozone yield monotonously decreases with increasing power. The maximal yield was observed at low powers. Figure 7 shows the generation of ozone as a function of discharge power for various input concentrations of oxygen. The most efficient generation of ozone was found for $10 \%$ oxygen mixtures at any discharge power. The efficiency of ozone generation decreased at high powers. The threshold of power, at which the decrease of ozone occurred, decreased with the concentration of initial oxygen.

The analysis of the gas mixtures by FTIR absorption spectroscopy showed that besides ozone various other by-products were generated depending on the input concentration of oxygen, gas flow rate and discharge power. In pure oxygen, no compounds other than ozone were found. In the mixtures with nitrogen, however, various amounts of $\mathrm{NO}_{2}, \mathrm{~N}_{2} \mathrm{O}_{5}, \mathrm{~N}_{2} \mathrm{O}$ and $\mathrm{HNO}_{3}$ were detected. The presence of the latter one can be explained by residual moisture in the system. The formation of NOx resulted from the reactions of nitrogen and oxygen atoms and molecules which are generated by the discharge, as the emission spectra in Figure 2 showed. Since the microdischarges are spark discharges with nonnegligible gas heating, the formation of NOx is difficult to suppress. The gas temperature even tends to increase with increasing oxygen concentration, due to the higher amplitudes of the discharge current pulses when compared with pure nitrogen. Therefore, higher energy delivered in a single discharge 
channel gave correspondingly higher gas temperatures [15].

The analysis of the FTIR spectra of the mixtures with $20 \%$ of oxygen and $1.2 \mathrm{~L} / \mathrm{min}$ showed that concentrations of ozone, $\mathrm{NO}_{2}$ and $\mathrm{N}_{2} \mathrm{O}_{5}$ increased with the discharge power. However, while the ozone concentration reached a certain maximum and then decreased (as shown in Fig. 6), the concentration of $\mathrm{NO}_{2}$ further increased from 7 to $54 \mathrm{ppm}$ for the discharge power of 1.1 and $9.2 \mathrm{~W}$, respectively. The corresponding ozone concentrations were 48 and $52 \mathrm{ppm}$, respectively. Figure 8 shows FTIR spectra of the mixture after the discharge action obtained for various discharge powers. Similar effect was observed for other gas flow rates; the only difference was that the maximal concentration of generated $\mathrm{NO}_{2}$ decreased with the gas flow rate (at the given power).

Considering the effect of the initial oxygen and comparing the ozone and NOx generation in various mixtures, we found less ozone and more NOx generated as the initial concentration of oxygen increased from 10 to $50 \% \mathrm{O}_{2}$ (see Fig. 9). This result is the consequence of the discharge homogeneity and distribution inside the ceramics and increased temperature, explained above.

\section{Conclusions}

The objective of the paper was to demonstrate the plasma chemical effects of the microplasmas generated by the $\mathrm{AC}$ discharges inside porous ceramic foams. We found the microplasmas effective for ozone generation. Maximal ozone generation and minimal formation of other by-products was found at low discharge power, high gas flow rates and paradoxically small concentrations of initial oxygen $(\sim 10 \%)$. The paradox was explained by the effect of oxygen on the discharge distribution and homogeneity and corresponding gas temperature. Microplasmas generated inside the ceramics are transient spark discharges and therefore produce certain amount of NOx. The production of NOx is critical especially at high energy densities. These conditions are not optimal for ozone generation, however, they can rather be effective for VOC treatment which is being subjected to further research. In addition, loading the foams with a catalyst can further improve the treatment efficiency and suppress the formation of undesired NOx. 


\section{Acknowledgments}

The research has been supported by the VEGA 1/3041/06, VEGA 1/0711/09, and APVV 0267-06 grants. The authors thank M. Leštinský (Comenius University) for technical assistance during experiments.

\section{References}

[1] K.H. Becker, U. Kogelschatz, K.H. Schoenbach, R.J. Barker, Non-Equilibrium Air Plasmas at Atmospheric Pressure (Institute of Physics Publishing, Bristol. 2005)

[2] K.H. Becker, K. H. Schoenbach, J. G. Eden, J. Phys. D: Appl. Phys. 39, R55 (2006)

[3] H.I. Park, T.I. Lee, K.W. Park, H.K. Baika, Appl. Phys. Lett. 82, 3191 (2003)

[4] P. Kurunczi, N. Abramzon, M. Figus, K. Becker, Acta Phys. Slovaca 54, 115(2004)

[5] A.D. Koutsospyros, S.M. Yin, C. Christodoulatos, K. Becker, IEEE Trans. Plasma Sci. 33, 42 (2005)

[6] M. Kraus, B. Eliasson, U. Kogelschatz, A. Wokaun, Chem. Phys. Chem. 3, 294 (2001)

[7] M.S. Lee, I.G. Koo, J.H. Kim, W.M. Lee, Int. J. Hydrogen Energy 34, 40 (2009)

[8] K. Hensel, S. Sato, A. Mizuno, IEEE Trans. Plasma Sci. 36, 1282 (2008)

[9] N. Blin-Simiand, P. Tardiveau, A. Risacher, F. Jorand, S. Pasquiers, Plasma Process. Polym. 2, $256(2005)$

[10] C. Ayrault, J. Barrault, N. Blin-Simiand, F. Jorand, S. Pasquiers, A. Rousseau, J.M. Tatibout, Catalysis Today 89, 75 (2004)

[11] U. Kogelschatz, Plasma Chem. Plasma Proces. 23, 1 (2003)

[12] M. Šimor, J. Ráhel', P. Vojtek, M. Černák, Appl. Phys. Lett. 81 , 2716 (2002)

[13] M. Černák, J. Ráhel', D. Kováčik, M. Šimor, A. Brablec, P. Slavíček, Contrib. Plasma Phys. 44, $492(2004)$

[14] K. Hensel, P. Tardiveau, IEEE Trans. Plasma Sci. 36, 980 (2008) 
[15] K. Hensel, V. Martišovitš, Z. Machala, M. Janda, M. Leštinský, P. Tardiveau, A. Mizuno, Plasma Process. Polym. 4, 682 (2007)

[16] K. Hensel, S. Katsura, A. Mizuno, IEEE Trans. Plasma Sci. 33, 574 (2005)

[17] K. Hensel, Y. Matsui, S. Katsura, A. Mizuno, Czech. J. Phys. 54, C683 (2004) 
FIGURE 1: Schematic view of experimental setup.

FIGURE 2: Emission spectra of microdischarges in the VIS-NIR region in mixtures with various amounts of oxygen [pore size $80 \mu \mathrm{m}, \mathrm{U} \sim 16.5 \mathrm{kV}$ ].

FIGURE 3: Ozone concentration in oxygen as a function of discharge power at various flow rates [pore size $\left.80 \mu \mathrm{m}, 100 \% \mathrm{O}_{2}\right]$.

FIGURE 4: Ozone generation in oxygen as a function of energy density for various flow rates [pore size $80 \mu \mathrm{m}$, $\left.100 \% \mathrm{O}_{2}\right]$.

FIGURE 5: Ozone concentration mixtures as a function of oxygen concentration (\%) in nitrogen at various flow rates $[50 \mu \mathrm{m}$ pore size, $\mathrm{P}=5 \sim 6 \mathrm{~W}]$.

FIGURE 6: Ozone concentration mixtures as a function of discharge power at various flow rates [50 $\mu \mathrm{m}$ pore size, $\left.20 \% \mathrm{O}_{2}\right]$.

FIGURE 7: Ozone concentration mixtures as a function of discharge power at various flow rates [50 $\mu \mathrm{m}$ pore size, $\mathrm{Q}=1.2 \mathrm{~L} / \mathrm{min}]$.

FIGURE 8: FTIR spectra of gas mixture after discharge action for various powers $[50 \mu \mathrm{m}$ pore size, $\mathrm{Q}=$ $\left.1.2 \mathrm{~L} / \mathrm{min}, 20 \% \mathrm{O}_{2}\right]$.

FIGURE 9: FTIR spectra of gas mixture after discharge action for input oxygen concentrations [50 $\mu \mathrm{m}$ pore size, $\mathrm{Q}=1.2 \mathrm{~L} / \mathrm{min}, \mathrm{P}=7 \sim 9 \mathrm{~W}]$. 


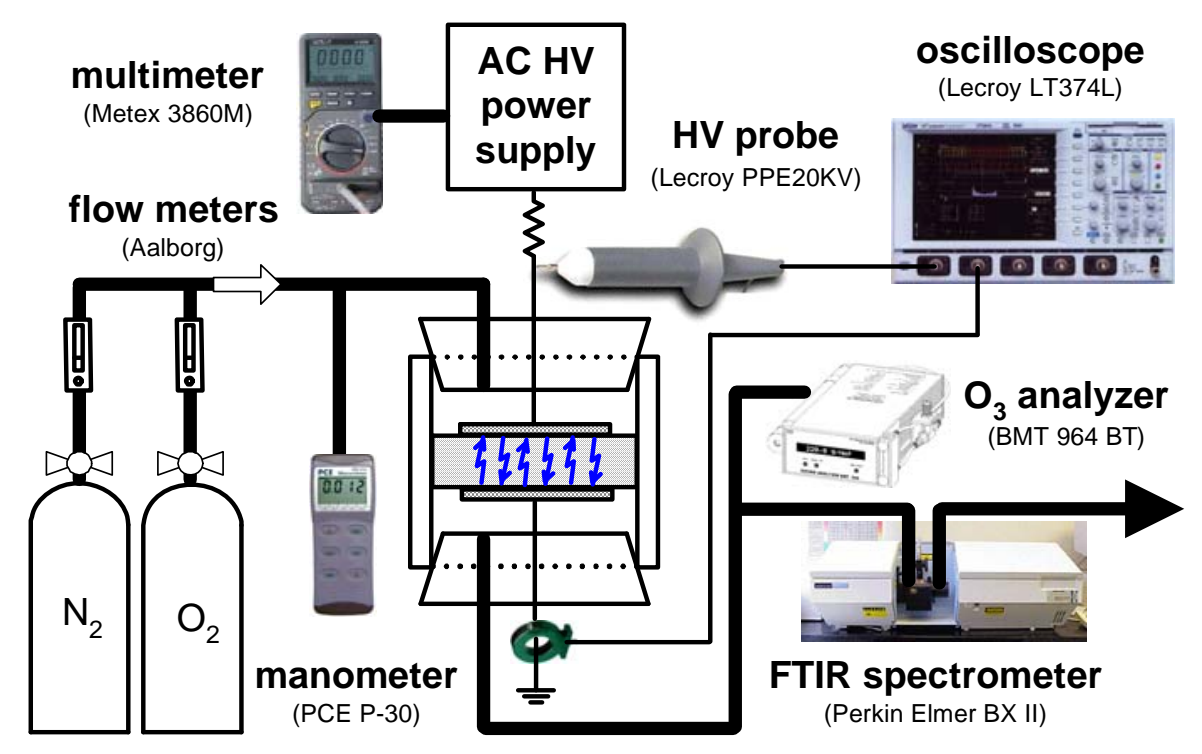

FIGURE 1: Schematic view of experimental setup.

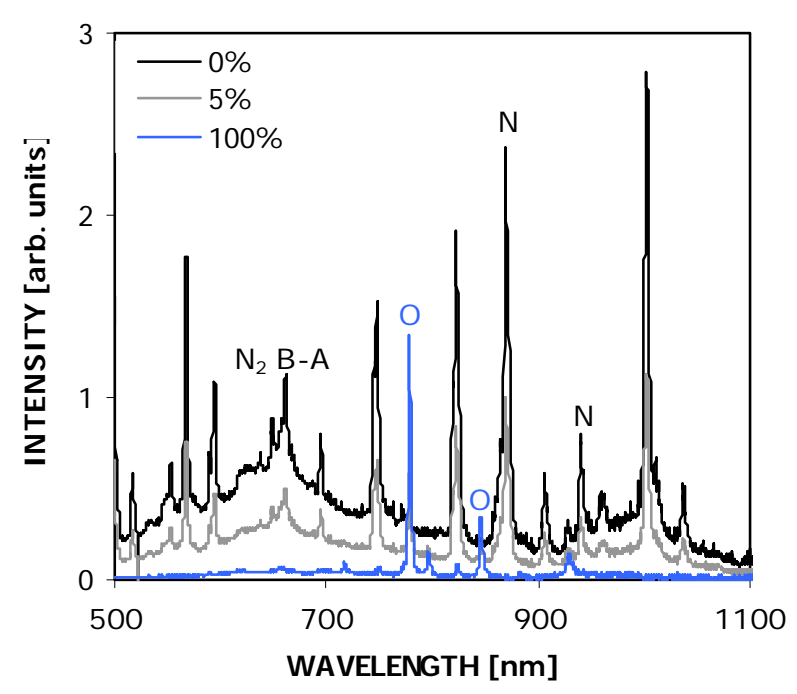

FIGURE 2: Emission spectra of microdischarges in the VIS-NIR region in mixtures with various amounts of oxygen [pore size $80 \mu \mathrm{m}, \mathrm{U} \sim 16.5 \mathrm{kV}$ ]. 


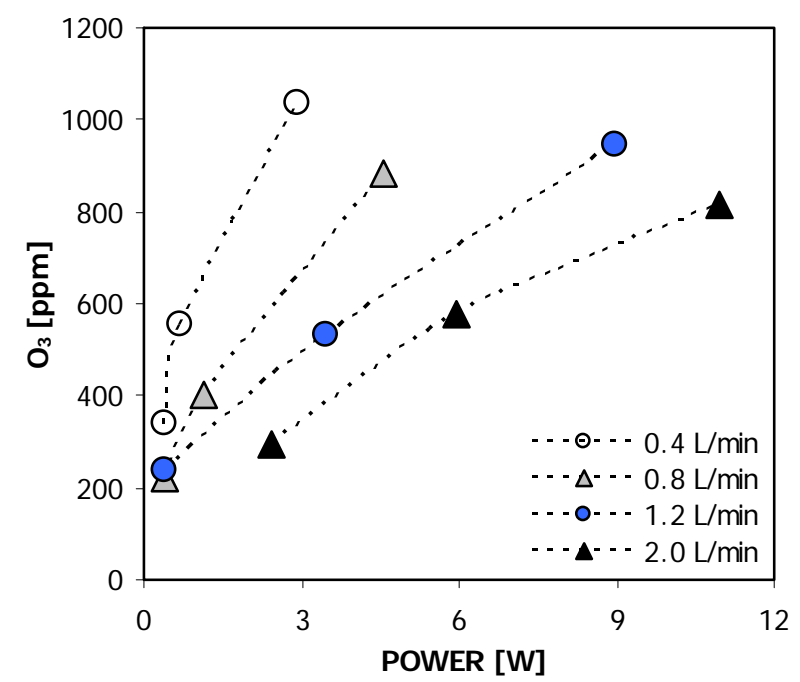

FIGURE 3: Ozone concentration in oxygen as a function of discharge power at various flow rates [pore size $\left.80 \mu \mathrm{m}, 100 \% \mathrm{O}_{2}\right]$.

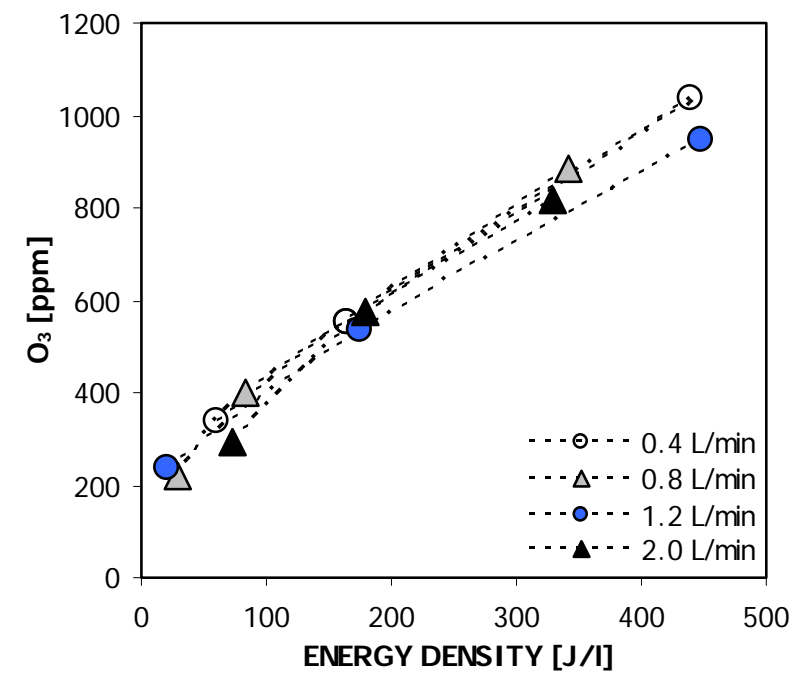

FIGURE 4: Ozone generation in oxygen as a function of energy density for various flow rates [pore size $80 \mu \mathrm{m}$, 
$\left.100 \% \mathrm{O}_{2}\right]$. 


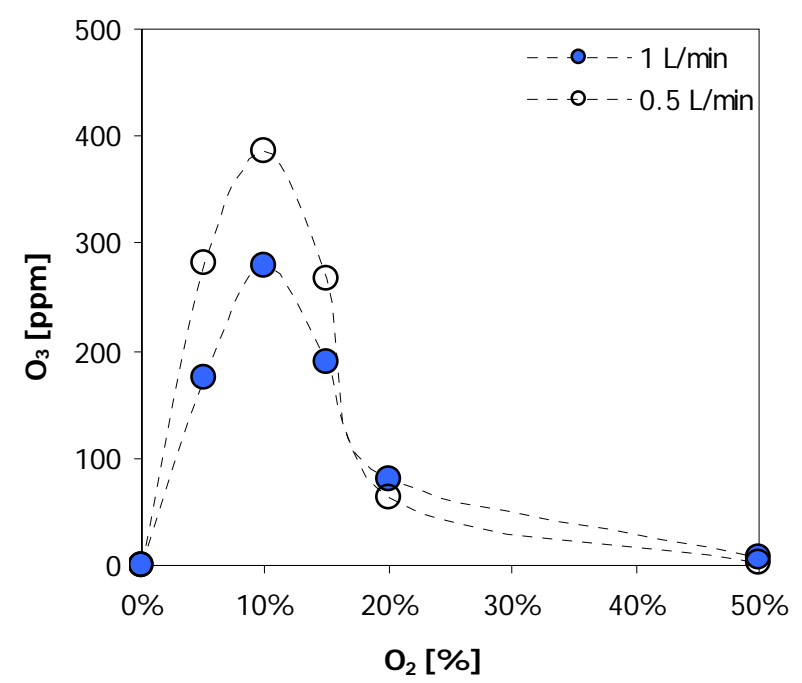

FIGURE 5: Ozone concentration mixtures as a function of oxygen concentration (\%) in nitrogen at various flow rates $[50 \mu \mathrm{m}$ pore size, $\mathrm{P}=5 \sim 6 \mathrm{~W}]$.

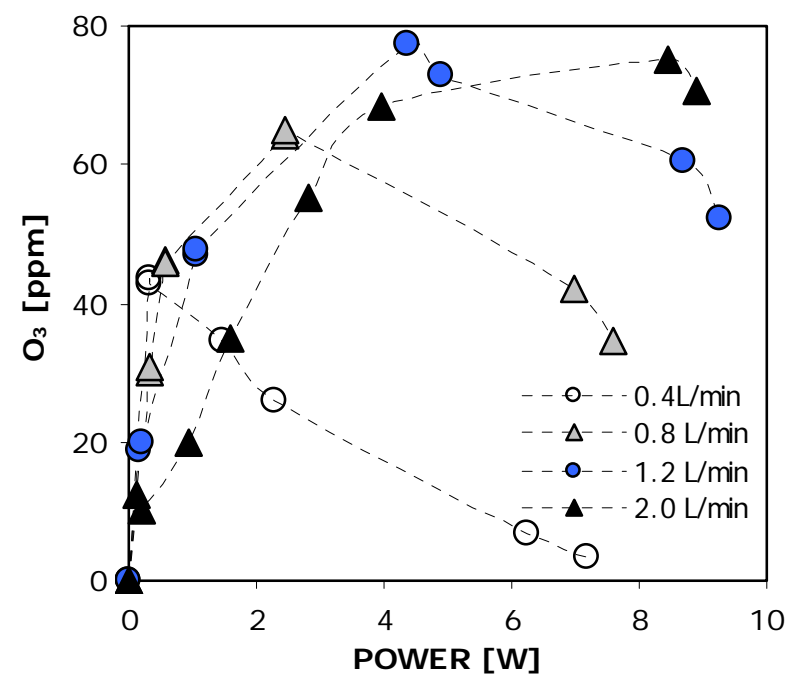

FIGURE 6: Ozone concentration mixtures as a function of discharge power at various flow rates [50 $\mu \mathrm{m}$ pore size, $\left.20 \% \mathrm{O}_{2}\right]$. 


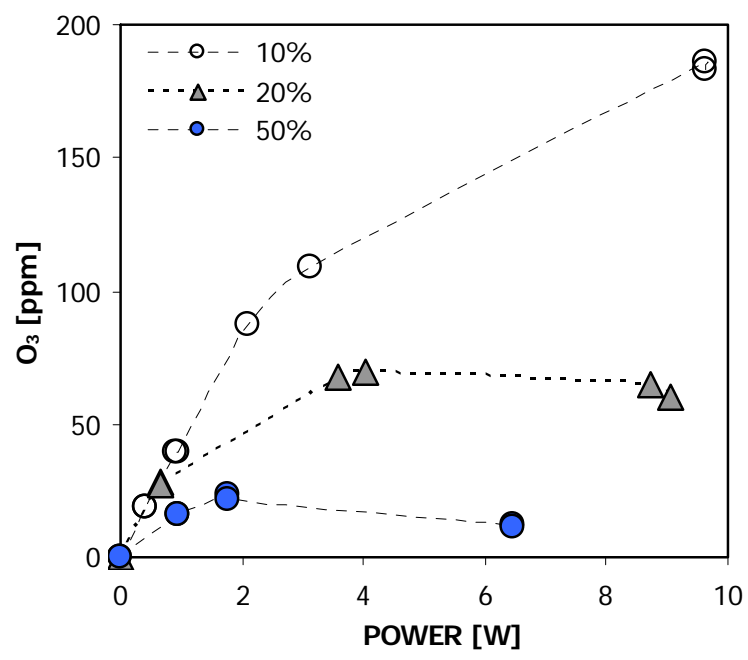

FIGURE 7: Ozone concentration mixtures as a function of discharge power at various flow rates [50 $\mu \mathrm{m}$ pore size, $\mathrm{Q}=1.2 \mathrm{~L} / \mathrm{min}]$.

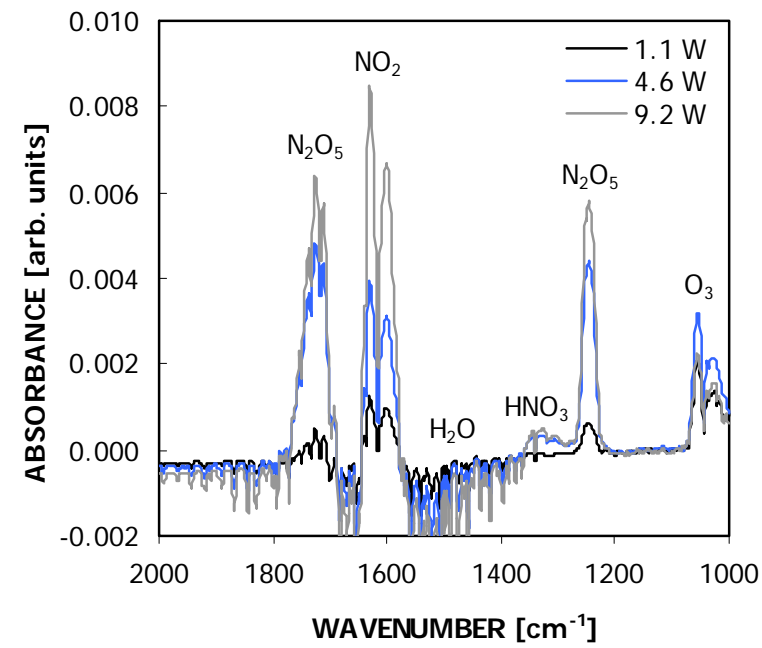

FIGURE 8: FTIR spectra of gas mixture after discharge action for various powers $[50 \mu \mathrm{m}$ pore size, $\mathrm{Q}=$ $\left.1.2 \mathrm{~L} / \mathrm{min}, 20 \% \mathrm{O}_{2}\right]$. 


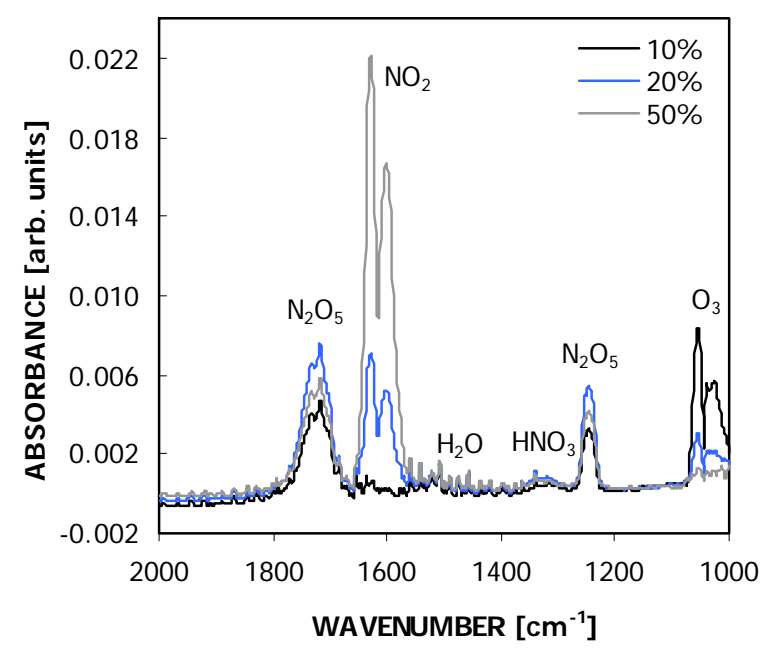

FIGURE 9: FTIR spectra of gas mixture after discharge action for input oxygen concentrations [50 $\mu \mathrm{m}$ pore size, $\mathrm{Q}=1.2 \mathrm{~L} / \mathrm{min}, \mathrm{P}=7 \sim 9 \mathrm{~W}]$. 